\title{
Avaliação do Desempenho e Rendimento de Carcaça de Quatro Linhagens de Frangos de Corte Criadas em Goiás
}

\author{
José Henrique Stringhini ${ }^{1,6}$, Michelle Laboissiére ${ }^{2}$, Keysuke Muramatsu ${ }^{3}$, Nadja Susana \\ Mogyca Leandro4, Marcos Barcellos Café 5
}

\begin{abstract}
RESUMO - Um experimento foi conduzido no Aviário Experimental do Abatedouro São Salvador, Itaberaí - GO, com o objetivo de se avaliarem os parâmetros de desempenho e qualidade de carcaça de quatro linhagens de frangos de corte. Foram avaliados o desempenho (41, 44 e 48 dias) e o rendimento de carcaça (41 e 44 dias) das linhagens Ross, Cobb, Arbor Acres e Avian Farms. O delineamento experimental adotado foi em blocos ao acaso num esquema fatorial 4x2 (linhagens x sexo) com quatro repetições de 63 aves para cada tratamento. Os resultados desse experimento apontaram desempenho e peso de carcaça superiores dos machos quando comparados às fêmeas, contudo nas características de rendimento de carcaça se mostraram semelhantes. A linhagem Ross teve ganho de peso e peso ao abate superiores às demais linhagens aos 44 dias de idade, mas isto não ocorreu nas demais fases. Não houve diferenças entre as linhagens em termos de rendimento de carcaça ou de cortes.
\end{abstract}

Palavras-chave: frango de corte, linhagem, desempenho, rendimento de carcaça

\section{Performance and Carcass Yield of Four Broiler Strains Raised in Goiás, Brazil}

\begin{abstract}
An experiment was carried out in the Abatedouro São Salvador, Goiás, Brazil, in order to evaluate the performance and carcass characteristics of four different broiler strains. The performance and carcass characteristics of Ross, Cobb, Avian Farms and Arbor Acres chickens were measured until 41, 44 and 48 days of age and the carcass parameters were measured at 41 and 44 days of age. Broilers were allotted in an randomized block design in a 4x2 factorial scheme (strains $\mathrm{x}$ sex) with four replicates of 63 birds each. It was observed better productive parameters and heavier body and carcass weight for male broilers than females, although no effect of sex occurred in carcass yield. Ross birds showed heavier body weight and higher cumulative weight gain at 44 days of age, but this was not observed in the other phases tested. There were no differences in commercial parts yield and carcass characteristics between the different strains.
\end{abstract}

Key Words: broiler, strain, performance, carcass yield

\section{Introdução}

A evolução e a competitividade da indústria avícola brasileira têm impulsionado a constante busca da melhoria do material genético das linhagens. Pesquisas avaliando esses produtos são realizadas a fim de identificar linhagens com características superiores em relação a outras, selecionando, assim, aves que apresentem não apenas um bom desempenho, mas também melhores rendimentos de carcaça e de cortes.

Conforme Rabello \& Cotta (1997), existem diversas linhagens de frangos de corte que apresentam diferenças de rendimento das partes nobres após o abate, quer seja pelo percentual de gordura localizado na região abdominal ou pelo percentual em dorso, afetando consideravelmente a rentabilidade da atividade quando o frango é comercializado em partes.

Os experimentos conduzidos com linhagens de frangos de corte e avaliações de cruzamentos são explorados na literatura científica mostrando ganhos em desempenho, mas principalmente em rendimento de carcaça e de cortes, o que mostra a preocupação dos geneticistas atuais com o desenvolvimento de linhagens competitivas para atender às exigências do mercado consumidor

\footnotetext{
1 Departamento de Produção Animal - Escola de Veterinária - Universidade Federal de Goiás, Caixa Postal 131, Campus II, Goiânia GO, 74001-970 (E.mail: henrique@vet.ufg.br)

2 Médica Veterinária, Abatedouro São Salvador, Itaberaí, Goiás (E.mail:michlab@zipmail.com.br)

3 Médico Veterinário, Perdigão Agroindustrial, Rio Verde, Goiás (E.mail: kmuramatsu@hotmail.com)

4 Departamento de Produção Animal - Escola de Veterinária - Universidade Federal de Goiás, Caixa Postal 131, Campus II, Goiânia GO, 74001-970 (E.mail: mogyca@vet.ufg.br)

5 Departamento de Produção Animal - Escola de Veterinária - Universidade Federal de Goiás, Caixa Postal 131, Campus II, Goiânia GO, 74001-970 (E.mail: mcafe@vet.ufg.br)

6 Bolsista do CNPq.
} 
(Silva, 1989; Bihan-Duval et al., 1998).

Segundo Murakami et al. (1995), pesquisas apontam uma melhoria em algumas linhagens e estagnação em outras. Os mesmos autores, em suas pesquisas, identificaram que as linhagens Ross e Cobb foram superiores a Hubbard em termos de desempenho e para algumas características de carcaça como rendimento de peito e filé de peito. Para o parâmetro rendimento de coxa e perna desossada, a linhagem Cobb mostrou-se como a melhor opção. Contudo, para a carcaça inteira (com pés, cabeça e pescoço) não foram detectadas diferenças significativas entre as três linhagens.

Rabello \& Cotta (1997) compararam as linhagens Hubbard, Isa e Cobb e identificaram efeito da linhagem no rendimento em coxas e sobrecoxas em que as linhagens Isa e Cobb apresentaram maiores valores para este parâmetro. Os mesmos autores observaram aumento do teor de gordura abdominal com a idade, sendo maior aos 42 dias. Os machos apresentaram maiores rendimentos em coxas e sobrecoxas e as fêmeas em peito e gordura abdominal.

Por outro lado, Mogyca et al. (1996), comparando o sexo e as linhagens Hubbard e Avian Farms, não detectaram diferenças estatísticas nos parâmetros de desempenho e rendimento de carcaça.

Rabello et al. (1996a) não encontraram efeito das linhagens Hubbard, Isa e Cobb no rendimento em gordura abdominal e vísceras comestíveis. Contudo, para o parâmetro rendimento em carcaça "pronta para assar", Cobb e Isa foram melhores que Hubbard, em virtude de maiores perdas ao abate desta última linhagem.

Com relação aos dados zootécnicos, Rabello et al. (1996b) demonstram que aos 42 dias de idade as linhagens Hubbard e Isa foram superiores à linhagem Cobb nos parâmetros ganho de peso, conversão alimentar, viabilidade e fator de produção.

Farran et al. (2000) mostraram que os frangos Ross, Lohmann e Arbor Acres apresentaram desempenho semelhante, sendo que a linhagem Ross permitiu maiores ganhos em rendimento de carcaça e menores teores de gordura abdominal em machos.

Tendo em vista o exposto, este trabalho foi conduzido com o objetivo de avaliar o desempenho zootécnico de quatro linhagens de frangos de corte criadas em condições experimentais em Itaberaí, Goiás, e as características de carcaça e o rendimento de cortes destas aves.

R. Bras. Zootec., v.32, n.1, p.183-190, 2003

\section{Material e Métodos}

Este experimento foi conduzido no Aviário Experimental de propriedade do Abatedouro São Salvador (Super-Frango) no município de Itaberaí - GO. Foram utilizados dois galpões de alvenaria com $24 \times 6,65 \mathrm{~m}$ de dimensões internas, divididos em 16 boxes de $2,10 \mathrm{x}$ $2,50 \mathrm{~m}$ cada, com tela de arame até a altura de $0,80 \mathrm{~m}$. Foi utilizada iluminação no esquema de três horas de escuro para nove horas com luz acesa à noite.

As rações foram formuladas à base de milho, farelo de soja e soja integral tostada atendendo às sugestões nutricionais adotadas pela integração (Tabela 1). O programa alimentar adotado foi o de quatro fases de criação de acordo com a idade das aves, sendo considerada fase pré-inicial a de 1 a 7 dias, inicial a de 8 a 21 dias, crescimento, a de 22 a 38 dias, e fase final, de 39 dias de idade ao abate, que variou de 41 a 48 dias de idade.

Foi utilizado o delineamento em blocos ao acaso, sendo o lado de cada galpão considerado como critério para escolha dos blocos, com oito tratamentos em um esquema fatorial 4 × 2 (linhagem x sexo), com quatro repetições por tratamento e 63 aves por boxe. As linhagens utilizadas foram Ross, Avian Farms, Cobb e Arbor Acres, compondo os tratamentos utilizados com sexo, machos e fêmeas.

Durante a condução do experimento procedeu-se à pesagem das aves e das rações no $1^{\circ}, 7^{\circ}, 21^{\circ}, 38^{\circ}$, $42^{\circ}, 44^{\circ}$ e $48^{\circ}$ dia de idade. O peso das aves mortas era registrado diariamente. Calcularam-se o ganho de peso, o consumo de ração, a conversão alimentar, a viabilidade criatória e o índice de eficiência produtiva ou fator de produção, pela fórmula abaixo:

\section{$I E P=\quad$ Ganho de peso $x$ Viabilidade $\quad x 100$ Idade ao abate $x$ Conversão alimentar}

Aos 41 dias de idade, cinco aves por repetição foram transportadas ao Abatedouro São Salvador em Itaberaí - GO para que fossem abatidas e avaliados os parâmetros relativos ao rendimento de carcaça. Procedeu-se à pesagem da ave viva na plataforma do abatedouro, da carcaça após sangria e depena e peso da carcaça eviscerada. Aos 44 dias de idade novamente cinco aves por repetição foram transportadas ao Abatedouro São Salvador realizando-se, além das peseagem citadas anteriormente, a dos pés + pescoço + cabeça, do peito, das coxas + sobrecoxas, do dorso e das asas. Os valores obtidos foram tabulados e 
Tabela 1 - Composição e níveis nutricionais das rações experimentais

Table 1 - Percentual and nutritional composition of the experimental rations

\begin{tabular}{|c|c|c|c|c|}
\hline $\begin{array}{l}\text { Ingrediente }(\%) \\
\text { Ingredient }\end{array}$ & $\begin{array}{c}\text { Pré-inicial } \\
(1-14 \mathrm{~d}) \\
\text { Pre-starter }\end{array}$ & $\begin{array}{l}\text { Inicial } \\
(14-21 \mathrm{~d}) \\
\text { Starter }\end{array}$ & $\begin{array}{c}\text { Crescimento } \\
(21-35 \mathrm{~d}) \\
\text { Growing }\end{array}$ & $\begin{array}{c}\text { Final } \\
(35-42 \mathrm{~d}) \\
\text { Finishing }\end{array}$ \\
\hline Milho (Corn) & 60,30 & 63,81 & 62,50 & 65,31 \\
\hline Farelo de gérmen desengordurado de milho & 0 & 0 & 10,00 & 15,00 \\
\hline \multicolumn{5}{|l|}{ Deffated corn germ meal } \\
\hline Farelo de soja (Soybean meal) & 30,8 & 20,80 & 9,30 & 7,10 \\
\hline Soja integral tostada (Toasted fullfat soybean) & 2,7 & 7,10 & 7,20 & 1,20 \\
\hline Farinha de carne e ossos $48 \%$ (Meat and bone meal 48\%) & 3,0 & 6,80 & 6,40 & 5,80 \\
\hline Farinha de sangue $80 \%$ (Blood meal $80 \%$ ) & 0 & 0 & 3,00 & 4,00 \\
\hline $\operatorname{Sal}($ Salt $)$ & 0,45 & 0,45 & 0,30 & 0,30 \\
\hline Calcário calcítico (Limestone) & 0,90 & 0,20 & 0,30 & 0,30 \\
\hline Fosfato bicálcico (Dicalcium phosphate) & 0,80 & 0 & 0 & 0 \\
\hline Bicarbonato de sódio (Sodium bicarbonate) & 0 & 0 & 0,15 & 0,15 \\
\hline DL-Metionina (DL-Methionine) & 0,21 & 0,21 & 0,18 & 0,13 \\
\hline L-Lisina $80 \%($ L-Lysine $80 \%)$ & 0 & 0,03 & 0,01 & 0,03 \\
\hline Suplemento vitamínico ${ }^{\mathrm{a}}$ (Vitamin supplement) & 0,06 & 0,05 & 0,05 & 0,05 \\
\hline Suplemento Mineral ${ }^{\mathrm{a}}$ (Mineral supplement) & 0,10 & 0,10 & 0,10 & 0,10 \\
\hline Veículo + Aditivos (Inert and feed additives) & 0,68 & 0,45 & 0,51 & 0,53 \\
\hline \multicolumn{5}{|l|}{ Níveis nutricionais (Nutritional levels) } \\
\hline Proteína $(\%)$ (Protein) & 21,96 & 21,03 & 19,90 & 17,98 \\
\hline $\mathrm{EM}(\mathrm{kcal} / \mathrm{kg})($ Metabolizable energy) & 2.938 & 3.036 & 3.094 & 3.110 \\
\hline Met + Cist $(\%)($ Met $+C y s)$ & 0,90 & 0,86 & 0,80 & 0,70 \\
\hline Metionina (\%) (Methionine) & 0,55 & 0,53 & 0,49 & 0,42 \\
\hline Lisina $(\%)($ Lysine $)$ & 1,174 & 1,105 & 1,052 & 0,948 \\
\hline Cálcio (\%) (Calcium) & 1,07 & 1,07 & 1,14 & 1,08 \\
\hline Fósforo disponível (\%) (Available phosphorus) & 0,41 & 0,51 & 0,52 & 0,50 \\
\hline
\end{tabular}

a Suplementos vitamínico e mineral, Nutron Alimentos, Campinas, SP.

a Vitamin and mineral supplements, Nutron Ailmentos, Campinas, SP.

apresentados em valores absolutos e em porcentagem do peso vivo das aves no abatedouro.

Os resultados obtidos foram submetidos à análise de variância e ao teste de comparação de médias de Tukey a $5 \%$ de probabilidade.

\section{Resultados e Discussão}

Não foram observadas interações significativas para os dados de desempenho avaliados. As análises de variância demonstraram efeito da linhagem $(\mathrm{P}<0,05)$ no ganho de peso de 1 a 7 dias e no consumo de ração no mesmo período e no período correspondente do primeiro ao $48^{\circ}$ dias de idade (Tabela 2 ). Murakami et al. (1995), comparando Ross, Cobb e Hubbard, não detectaram diferenças no peso final aos 45 dias entre Ross e Cobb. Para as outras idades (41 e 48 dias) não foram observadas diferenças estatísticas no peso das aves entre os diferentes grupos genéticos. Souza et al. (1994) detectaram pesos superiores dos machos Ross em relação a Arbor Acres aos 41 dias de idade e superiores a Arbor Acres e Cobb aos 49 dias de idade.

As linhagens Avian Farms e Arbor Acres apresentaram um consumo acumulado de ração mais elevado aos 48 dias de idade. Nessa fase, frangos Arbor Acres e Avian Farms apresentaram um consumo acumulado de ração estatisticamente superior à linhagem Cobb em 168,65 e 148,49 gramas, respectivamente $(\mathrm{P}<0,05)$. Esses resultados são contrários aos obtidos por Souza et al. (1994), que detectaram maior consumo de ração para $\mathrm{Cobb}$ em relação à Arbor Acres aos 41 e 49 dias de idade.

A linhagem Ross obteve melhor conversão alimentar (1.667) em relação às linhagens Avian Farms $(1,779)$ e Arbor Acres $(1,780)$ de 1 a 44 dias de idade (Tabela 2). Holsheimer \& Veerkamp (1992) e Souza et al. (1994) detectaram melhor conversão alimentar de frangos Ross quando comparados com Cobb.

Como esperado, o desempenho dos machos foi 
superior às fêmeas (Tabela 3$)$ em todos os períodos estudados $(\mathrm{P}<0,05)$. As fêmeas dos frangos de corte acumulam maior quantidade de gordura corporal, o que compromete seu ganho de peso e conversão alimentar.

Verifica-se na Tabela 4 que o peso das carcaças e suas percentagens em relação ao peso vivo aos 41 dias de idade não foram influenciados pelos grupos genéticos. Mogyca et al. (1996), ao compararem as linhagens Hubbard e Avian Farms, também não detectaram efeito da linhagem no parâmetro de rendimento de carcaça. De forma similar, em pesquisas conduzidas por Murakami et al. (1995), analisando três linhagens de frangos de corte, não foi apontado efeito da linhagem no parâmetro carcaça eviscerada com pés, pescoço e cabeça.

Por outro lado, o efeito do sexo foi marcante. Os machos apresentaram maiores peso de carcaça e melhor rendimento de carcaça expresso em termos de carcaça eviscerada/peso vivo e carcaça eviscerada/ carcaça depenada e sangrada (Tabela 4).

Novamente, os pesos das carcaças e suas percentagens em relação ao peso vivo aos 44 dias de idade (Tabela 5) não foram influenciados pelos grupos genéticos. Mendes et al. (1993), comparando as linhagens Hubbard e Arbor Acres, também não encontraram diferenças no peso e rendimento da carcaça eviscerada.

Tabela 2 - Desempenho cumulativo de frangos de corte de diferentes linhagens ${ }^{1}$

Table 2 - Cumulative performance of broilers from different genetic strains ${ }^{1}$

\begin{tabular}{|c|c|c|c|c|c|c|c|c|}
\hline \multirow[b]{3}{*}{ Peso médio $(\mathrm{g})$} & Ross & Cobb A & Avian Farms & Arbor Acres & Ross & Cobb & Avian Farms & Arbor Acres \\
\hline & \multicolumn{4}{|c|}{$1-7$ dias (1 to 7 days $)$} & \multicolumn{4}{|c|}{$1-14$ dias (1 to 14 days) } \\
\hline & 171,79 & 173,82 & 167,13 & 169,82 & 416,23 & 416,25 & 409,83 & 414,70 \\
\hline \multicolumn{9}{|l|}{ Mean weight ( $g$ ) } \\
\hline $\begin{array}{l}\text { Ganho de peso (g) } \\
\text { Weight gain }(g)\end{array}$ & $125,48 \mathrm{ab}$ & $128,59 a$ & $124,67 \mathrm{ab}$ & $120,93 b$ & 369,90 & 371,01 & 363,63 & 369,55 \\
\hline $\begin{array}{l}\text { Consumo de ração }(\mathrm{g}) \\
\text { Feed intake }(\mathrm{g})\end{array}$ & $145,25 \mathrm{ab}$ & $151,04 a$ & $144,95 b$ & $146,40 \mathrm{ab}$ & 496,48 & 512,32 & 499,30 & 503,32 \\
\hline \multirow[t]{2}{*}{$\begin{array}{l}\text { Conversão alimentar } \\
\text { Feed-to-gain ratio }\end{array}$} & 1,168 & 1,185 & 1,204 & 1,176 & 1,354 & 1,391 & 1,380 & 1,365 \\
\hline & \multicolumn{4}{|c|}{$1-21$ dias (1 to 21 days) } & \multicolumn{4}{|c|}{$1-28$ dias (1 to 28 days) } \\
\hline \multicolumn{9}{|l|}{ Mean weight (g) } \\
\hline \multicolumn{8}{|l|}{ Weight gain $(g)$} & 1197,11 \\
\hline \multicolumn{9}{|l|}{ Feed intake (g) } \\
\hline \multicolumn{9}{|l|}{ Feed-to-gain ratio } \\
\hline & \multicolumn{4}{|c|}{$1-35$ dias (1 to 35 days) } & \multicolumn{4}{|c|}{$1-41$ dias (1 to 41 days) } \\
\hline $\begin{array}{l}\text { Peso médio }(\mathrm{g}) \\
\text { Mean weight }(g)\end{array}$ & 1721,14 & 1734,28 & 1731,28 & 1709,04 & 2109,23 & 2143,94 & 2126,25 & 2058,13 \\
\hline $\begin{array}{l}\text { Ganho de peso }(\mathrm{g}) \\
\text { Weight gain }(\mathrm{g})\end{array}$ & 1674,80 & 1689,04 & 1685,58 & 1663,89 & 2062,89 & 2098,71 & 2080,05 & 2012,98 \\
\hline $\begin{array}{l}\text { Consumo de ração }(\mathrm{g}) \\
\text { Feed intake }(\mathrm{g})\end{array}$ & 2820,84 & 2748,28 & 2809,35 & 2830,55 & 3432,17 & 3392,76 & 3470,10 & 3501,86 \\
\hline \multirow[t]{2}{*}{$\begin{array}{l}\text { Conversão alimentar } \\
\text { Feed-to-gain ratio }\end{array}$} & 1,700 & 1,644 & 1,684 & 1,713 & 1,683 & 1,637 & 1,682 & 1,760 \\
\hline & \multicolumn{4}{|c|}{$1-44$ dias (1 to 44 days) } & \multicolumn{4}{|c|}{$1-48$ dias (1 to 48 days) } \\
\hline $\begin{array}{l}\text { Peso médio }(\mathrm{g}) \\
\text { Mean weight }(g)\end{array}$ & 2386,59 & 2308,85 & 2265,58 & 2279,62 & 2549,66 & 2497,72 & 2525,89 & 2509,56 \\
\hline $\begin{array}{l}\text { Ganho de peso (g) } \\
\text { Weight gain }(g)\end{array}$ & 2340,25 & 2263,61 & 2219,38 & 2234,47 & 2503,33 & 2452,48 & 2479,69 & 2464,41 \\
\hline $\begin{array}{l}\text { Consumo de ração }(\mathrm{g}) \\
\text { Feed intake }(\mathrm{g})\end{array}$ & 3861,10 & 3824,33 & 3918,75 & 3938,57 & $4407,84 \mathrm{ab}$ & b4311,16b & $4459,65 a$ & $4479,81 \mathrm{a}$ \\
\hline $\begin{array}{l}\text { Conversão alimentar } \\
\text { Feed-to-gain ratio }\end{array}$ & $1,667 b$ & $1,713 \mathrm{ab}$ & $1,779 \mathrm{a}$ & $1,780 \mathrm{a}$ & 1,779 & 1,778 & 1,816 & 1,835 \\
\hline
\end{tabular}

\footnotetext{
${ }^{1}$ Letras diferentes nas linhas indicam diferença estatística significativa (Tukey, $5 \%$ ).

${ }^{1}$ Different letters in the rows indicate statistical difference (Tukey, 5\%).

${ }^{2} \mathrm{CV}=$ coeficiente de variação.

${ }^{2} \mathrm{CV}=$ coefficient of variation
}

\section{R. Bras. Zootec., v.32, n.1, p.183-190, 2003}


Tabela 3 - Desempenho cumulativo de frangos de corte, de acordo com o sexo ${ }^{1}$

Table 3 - Cumulative performance of broilers, according to sex ${ }^{1}$

\begin{tabular}{|c|c|c|c|c|c|c|c|c|}
\hline & $\begin{array}{l}\text { Machos } \\
\text { Males }\end{array}$ & $\begin{array}{l}\text { Fêmeas } \\
\text { Females }\end{array}$ & $\begin{array}{l}\text { Machos } \\
\text { Males }\end{array}$ & $\begin{array}{l}\text { Fêmeas } \\
\text { Females }\end{array}$ & $\begin{array}{l}\text { Machos } \\
\text { Males }\end{array}$ & $\begin{array}{l}\text { Fêmeas } \\
\text { Females }\end{array}$ & $\begin{array}{l}\text { Machos } \\
\text { Males }\end{array}$ & $\begin{array}{l}\text { Fêmeas } \\
\text { Females }\end{array}$ \\
\hline & \multicolumn{2}{|c|}{$1-7$ dias } & \multicolumn{2}{|c|}{$1-14$ dias } & \multicolumn{2}{|c|}{$1-21$ dias } & \multicolumn{2}{|c|}{$1-28$ dias } \\
\hline Peso médio (g) & $173,06 a$ & $168,22 b$ & $423,64 a$ & $404,87 b$ & $812,19 \mathrm{a}$ & $719,16 b$ & $1341,03 a$ & $1175,19 b$ \\
\hline $\begin{array}{l}\text { Mean weight }(g) \\
\text { Ganho de peso }(\mathrm{g}) \\
\text { Weight gain }(g)\end{array}$ & $127,18 \mathrm{a}$ & $122,63 b$ & $377,76 \mathrm{a}$ & $359,28 b$ & $766,31 \mathrm{a}$ & $673,57 b$ & $1295,16 a$ & $1129,50 \mathrm{~b}$ \\
\hline $\begin{array}{l}\text { Consumo de ração }(\mathrm{g}) \\
\text { Feed intake }(\mathrm{g})\end{array}$ & $148,87 \mathrm{a}$ & $144,95 b$ & $511,32 \mathrm{a}$ & $494,39 b$ & $1125,20 \mathrm{a}$ & $1036,75 b$ & $985,12 \mathrm{a}$ & $1816,75 b$ \\
\hline \multirow[t]{2}{*}{$\begin{array}{l}\text { Conversão alimentar } \\
\text { Feed-to-gain ratio }\end{array}$} & 1,174 & 1,193 & 1,360 & 1,385 & $1,475 b$ & $1,547 \mathrm{a}$ & $1,545 b$ & $1,614 \mathrm{a}$ \\
\hline & \multicolumn{2}{|c|}{$1-35$ dias } & \multicolumn{2}{|c|}{$1-41$ dias } & \multicolumn{2}{|c|}{$1-44$ dias } & \multicolumn{2}{|c|}{$1-48$ dias } \\
\hline $\begin{array}{l}\text { Peso médio }(\mathrm{g}) \\
\text { Mean weight }(g)\end{array}$ & $864,57 \mathrm{a}$ & $1583,55 b$ & $2220,96 a$ & $1997,81 b$ & $2494,38 \mathrm{a}$ & $2125,94 b$ & $2731,84 \mathrm{a}$ & $2309,58 b$ \\
\hline $\begin{array}{l}\text { Ganho de peso }(\mathrm{g}) \\
\text { Weight gain }(g)\end{array}$ & $1818,69 \mathrm{a}$ & $1537,96 b$ & $2175,09 a$ & $1952,23 b$ & $2448,50 \mathrm{a}$ & $2080,35 b$ & $2685,96 a$ & $2263,99 b$ \\
\hline $\begin{array}{l}\text { Consumo de ração }(\mathrm{g}) \\
\text { Feed intake }(\mathrm{g})\end{array}$ & $2971,70 \mathrm{a}$ & $2632,81 b$ & $3670,25 a$ & $3228,20 b$ & $4118,90 \mathrm{a}$ & $3652,47 b$ & $4682,82 \mathrm{a}$ & $4146,41 b$ \\
\hline $\begin{array}{l}\text { Conversão alimentar } \\
\text { Feed-to-gain ratio }\end{array}$ & $1,648 b$ & $1,723 \mathrm{a}$ & 1,708 & 1,673 & $1,699 b$ & $1,771 \mathrm{a}$ & $1,760 \mathrm{~b}$ & $1,844 a$ \\
\hline
\end{tabular}

${ }^{1}$ Letras diferentes nas linhas indicam diferença estatística significativa.

${ }^{1}$ Minor letters in the rows indicates statistical difference.

$\mathrm{CV}=$ coeficiente de variação.

$C V=$ coefficient of variation

Tabela 4 - Peso vivo, peso das carcaças (em gramas) e relação peso de carcaça/peso vivo (\%) de diferentes linhagens aos 41 dias de idade 1

Table 4 - Live body weight (grams), carcass weight and carcass weight/live weight relation (\%) of different strains at 41 days of age 1

Peso vivo no abatedouro Carcaça depenada e sangrada Carcaça eviscerada com
Live weight at slaughterhouse Bled and defeathered carcass pé+pescoço+cabeça

Eviscerated carcass with

\begin{tabular}{|c|c|c|c|c|c|c|c|c|c|}
\hline & \multirow[b]{2}{*}{$\begin{array}{c}\text { Macho } \\
\text { Male }\end{array}$} & \multirow[b]{2}{*}{$\begin{array}{l}\text { Fêmea } \\
\text { Female }\end{array}$} & \multirow[b]{2}{*}{$\begin{array}{l}\text { Média } \\
\text { Mean }\end{array}$} & \multirow[b]{2}{*}{$\begin{array}{c}\text { Macho } \\
\text { Male }\end{array}$} & \multirow[b]{2}{*}{$\begin{array}{l}\text { Fêmea } \\
\text { Female }\end{array}$} & \multirow[b]{2}{*}{$\begin{array}{l}\text { Média } \\
\text { Mean }\end{array}$} & \multicolumn{3}{|c|}{ feet, neck and head } \\
\hline & & & & & & & $\begin{array}{c}\text { Macho } \\
\text { Male }\end{array}$ & $\begin{array}{l}\text { Fêmea } \\
\text { Female }\end{array}$ & $\begin{array}{l}\text { Média } \\
\text { Mean }\end{array}$ \\
\hline Ross & 2242 & 1926 & 2084 & 2024 & 1740 & 1882 & 1784 & 1515 & 1650 \\
\hline Cobb & 2180 & 1880 & 2030 & 1975 & 1703 & 1839 & 1748 & 1487 & 1618 \\
\hline A. Farms & 2190 & 1822 & 2006 & 1969 & 1650 & 1809 & 1733 & 1440 & 1587 \\
\hline A. Acres & 2170 & 1922 & 2046 & 1973 & 1742 & 1857 & 1737 & 1513 & 1625 \\
\hline Média (Mean) & $2196 a$ & $1887 \mathrm{~b}$ & & $1985 a$ & $1709 \mathrm{~b}$ & & $1750 \mathrm{a}$ & $1489 \mathrm{~b}$ & \\
\hline $\mathrm{CV} \%$ & & 4,43 & & & 4,44 & & & 4,66 & \\
\hline
\end{tabular}

\begin{tabular}{|c|c|c|c|c|c|c|c|c|c|}
\hline \multirow[t]{3}{*}{$\mathrm{CV} \%$} & \multirow{2}{*}{\multicolumn{3}{|c|}{$\begin{array}{c}4,43 \\
\text { C. depenada }+ \text { sangrada/PV } \\
\text { Bled, defeatherd carcass } / \\
\text { body weight }\end{array}$}} & \multirow{2}{*}{\multicolumn{3}{|c|}{$\begin{array}{c}4,44 \\
\text { C. eviscerada/PV } \\
\text { Eviscerated carcass/ } \\
\text { body weight }\end{array}$}} & \multirow{2}{*}{\multicolumn{3}{|c|}{$\begin{array}{c}4,66 \\
\text { C. eviscerada/C. depenada } \\
\text { e sangrada } \\
\text { Eviscerated carcass/ } \\
\text { bled defeathered carcass }\end{array}$}} \\
\hline & & & & & & & & & \\
\hline & $\begin{array}{c}\text { Macho } \\
\text { Male }\end{array}$ & $\begin{array}{l}\text { Fêmea } \\
\text { Female }\end{array}$ & $\begin{array}{l}\text { Média } \\
\text { Mean }\end{array}$ & $\begin{array}{c}\text { Macho } \\
\text { Male }\end{array}$ & $\begin{array}{l}\text { Fêmea } \\
\text { Female }\end{array}$ & $\begin{array}{l}\text { Média } \\
\text { Mean }\end{array}$ & $\begin{array}{c}\text { Macho } \\
\text { Male }\end{array}$ & $\begin{array}{l}\text { Fêmea } \\
\text { Female }\end{array}$ & $\begin{array}{l}\text { Média } \\
\text { Mean }\end{array}$ \\
\hline Ross & 90,29 & 90,38 & 90,33 & 79,58 & 78,65 & 79,11 & 88,14 & 87,03 & 87,58 \\
\hline Cobb & 90,58 & 90,62 & 90,60 & 80,19 & 79,10 & 79,64 & 88,53 & 88,04 & 88,29 \\
\hline A. Farms & 89,92 & 90,51 & 90,21 & 79,15 & 79,01 & 79,08 & 88,01 & 87,30 & 87,66 \\
\hline A. Acres & 90,64 & 90,59 & 90,61 & 79,79 & 78,61 & 79,20 & 87,96 & 86,78 & 87,37 \\
\hline Média (Mean) & 90,35 & 90,52 & & $79,68 \mathrm{a}$ & $78,84 b$ & & $88,16 \mathrm{a}$ & $87,29 b$ & \\
\hline CV\% & & 0,73 & & & 0,99 & & & 0,78 & \\
\hline
\end{tabular}

1 Letras diferentes nas linhas indicam diferença estatística significativa.

${ }^{1}$ Minor letters in the rows indicates statistical difference.

$\mathrm{CV}=$ coeficiente de variação.

$\mathrm{CV}=$ coefficient of variation.

R. Bras. Zootec., v.32, n.1, p.183-190, 2003 
Nas medições realizadas aos 44 dias de idade observou-se que os machos apresentaram maiores pesos de carcaças em virtude do seu maior peso vivo. Contudo, o rendimento de carcaça, expresso em termos de percentagem de carcaça depenada e sangrada/PV, carcaça eviscerada/PV e carcaça eviscerada sem pés, pescoço e cabeça/PV, não sofreu efeito do sexo (Tabela 5).

As diferentes linhagens não influenciaram o peso e o rendimento dos diferentes cortes em relação ao peso vivo (Tabelas 5 e 6). Da mesma forma, Souza et al. (1994) não observaram diferenças estatísticas entre as linhagens Ross, Hubbard, Cobb e Arbor Acres no que se refere ao rendimento de asa, pernas e cabeça + pescoço + pés. Entretanto, conforme esses autores, o rendimento em filé de peito foi influenciado pela linhagem, sendo que os piores resultados foram observados para a linhagem Arbor Acres.

Por outro lado, verificou-se efeito do sexo sobre determinados cortes. Os machos apresentaram maiores pesos e rendimento de coxa + sobrecoxa e de asas (Tabela 6). Da mesma forma, Mendes et al. (1993), Murakami et al. (1995) e Rabello \& Cotta (1997) detectaram em suas pesquisas que o peso e a percentagem de coxa + sobrecoxa foram maiores nos machos quando comparados às fêmeas.

Apesar dos maiores pesos e rendimento de carcaça dos machos, observou-se também o aumento, na composição da carcaça, de porções pouco valorizadas como os cortes de cabeça + pés + pescoço e dorso (Tabela 7). Estes resultados estão de acordo com Mendes (1990), Mendes et al. (1993) e Murakami et al. (1995), que também observaram maior proporção de cabeça, pescoço e pés para os machos.

Tabela 5 - Peso vivo e da carcaça (em gramas) e a relação (\%) entre pesos vivos e de carcaça das diferentes linhagens aos 44 dias de idade

Table 5 - Carcass weight (grams) and relation (\%) between carcass weight and Live body weight of different strains at 44 days of age

\begin{tabular}{|c|c|c|c|c|c|c|c|c|c|}
\hline & \multicolumn{3}{|c|}{$\begin{array}{l}\text { Carcaça depen. sang. } \\
\text { Bled defeathered carcass }\end{array}$} & \multicolumn{3}{|c|}{$\begin{array}{l}\text { Carcaça eviscerada } \\
\text { Eviscerated carcass }\end{array}$} & \multicolumn{3}{|c|}{$\begin{array}{c}\text { Carcaça eviscerada. s/ cabeça, } \\
\text { pescoço, pés } \\
\text { Eviscerated carcass without } \\
\text { feet }+ \text { neck+head }\end{array}$} \\
\hline & Macho & Fêmea & Média & Macho & Fêmea & Média & Macho & Fêmea & Média \\
\hline & Male & Female & Mean & Male & Female & Mean & Male & Female & Mean \\
\hline$\overline{\text { Ross }}$ & 2297 & 1955 & 2126 & 2037 & 1740 & 1889 & 1780 & 1538 & 1659 \\
\hline Cobb & 2222 & 1921 & 2071 & 2007 & 1675 & 1841 & 1750 & 1481 & 1615 \\
\hline A. Farms & 2242 & 1908 & 2075 & 1994 & 1664 & 1829 & 1738 & 1478 & 1608 \\
\hline A. Acres & 2259 & 1953 & 2106 & 1969 & 1709 & 1839 & 1741 & 1505 & 1623 \\
\hline Média (Mean) & $2255 a$ & $1934 b$ & - & $2002^{\mathrm{a}}$ & $1697 b$ & - & $1752 \mathrm{a}$ & $1501 b$ & - \\
\hline \multirow[t]{3}{*}{$\mathrm{CV} \%$} & & 3,16 & & & 3,50 & & & 3,50 & \\
\hline & \multicolumn{3}{|c|}{$\begin{array}{l}\text { Carcaça depenada e sangrada/PV } \\
\text { Bled, defeathered carcass/body weight }\end{array}$} & \multicolumn{3}{|c|}{$\begin{array}{c}\text { Carcaça eviscerada/PV } \\
\text { Eviscerated carcass/body weight }\end{array}$} & \multicolumn{3}{|c|}{$\begin{array}{c}\text { Carcaça eviscerada } \\
\mathrm{s} / \text { cabeça, pescoço, pés/PV } \\
\text { Eviscerated carcass without } \\
\text { head }+ \text { neck }+ \text { head/body weight }\end{array}$} \\
\hline & $\begin{array}{l}\text { Macho } \\
\text { Male }\end{array}$ & $\begin{array}{l}\text { Fêmea } \\
\text { Female }\end{array}$ & $\begin{array}{l}\text { Média } \\
\text { Mean }\end{array}$ & $\begin{array}{l}\text { Macho } \\
\text { Male }\end{array}$ & $\begin{array}{l}\text { Fêmea } \\
\text { Female }\end{array}$ & $\begin{array}{l}\text { Média } \\
\text { Mean }\end{array}$ & $\begin{array}{l}\text { Macho } \\
\text { Male }\end{array}$ & $\begin{array}{l}\text { Fêmea } \\
\text { Female }\end{array}$ & $\begin{array}{l}\text { Média } \\
\text { Mean }\end{array}$ \\
\hline Ross & 91,19 & 89,20 & 90,20 & 80,88 & 79,40 & 80,14 & 70,69 & 70,16 & 70,42 \\
\hline Cobb & 89,48 & 90,86 & 90,17 & 80,83 & 79,22 & 80,03 & 70,46 & 70,04 & 70,25 \\
\hline A. Farms & 87,31 & 90,69 & 89,00 & 77,63 & 79,08 & 78,36 & 67,71 & 70,27 & 68,99 \\
\hline A. Acres & 90,64 & 89,80 & 90,22 & 80,43 & 78,62 & 79,52 & 69,83 & 69,23 & 69,53 \\
\hline Média (Mean) & 89,66 & 90,14 & - & 79,94 & 79,08 & - & 69,67 & 69,92 & - \\
\hline $\mathrm{CV} \%$ & & 2,96 & & & 2,83 & & & 3,07 & \\
\hline
\end{tabular}

Letras diferentes nas linhas indicam diferença estatística significativa.

Minor letters in the rows indicates statistical difference.

$\mathrm{CV}=$ coeficiente de variação

$C V=$ coefficient of variation. 
Tabela 6 - Peso dos cortes (em gramas) e suas relações com o peso vivo (PV) aos 44 dias de idade Table 6 - Cuts weight (grams) and relation (\%) between cuts weight and live body weight at 44 days of age

\begin{tabular}{|c|c|c|c|c|c|c|c|c|c|c|c|c|}
\hline & \multicolumn{3}{|c|}{$\begin{array}{l}\text { Peito } \\
\text { Breast }\end{array}$} & \multicolumn{3}{|c|}{$\begin{array}{l}\text { Peito/peso vivo } \\
\text { Breast/body weight }\end{array}$} & \multicolumn{3}{|c|}{$\begin{array}{l}\text { Coxa }+ \text { sobrecoxa } \\
\text { Legs }+ \text { drumsticks }\end{array}$} & \multicolumn{3}{|c|}{$\begin{array}{l}\text { Coxa }+ \text { sobrecoxa/peso vivo } \\
\text { Legs }+ \text { drumsticks/body weight }\end{array}$} \\
\hline & $\begin{array}{l}\text { Macho } \\
\text { Male }\end{array}$ & $\begin{array}{l}\text { Fêmea } \\
\text { Female }\end{array}$ & $\begin{array}{l}\text { Média } \\
\text { Mean }\end{array}$ & $\begin{array}{l}\text { Macho } \\
\text { Male }\end{array}$ & $\begin{array}{l}\text { Fêmea } \\
\text { Female }\end{array}$ & $\begin{array}{l}\text { Média } \\
\text { Mean }\end{array}$ & $\begin{array}{l}\text { Macho } \\
\text { Male }\end{array}$ & $\begin{array}{l}\text { Fêmea } \\
\text { Female }\end{array}$ & $\begin{array}{l}\text { Média } \\
\text { Mean }\end{array}$ & $\begin{array}{l}\text { Macho } \\
\text { Male }\end{array}$ & $\begin{array}{l}\text { Fêmea } \\
\text { Female }\end{array}$ & $\begin{array}{l}\text { Média } \\
\text { Mean }\end{array}$ \\
\hline Ross & 444,0 & 507,2 & 475,6 & 22,59 & 23,15 & 22,87 & 567,7 & 436,4 & 502,0 & 22,55 & 21,01 & 21,78 \\
\hline Cobb & 565,5 & 496,5 & 531,0 & 22,79 & 23,48 & 23,13 & 568,2 & 452,3 & 510,2 & 22,89 & 21,39 & 22,14 \\
\hline A. Farms & 577,0 & 489,6 & 533,3 & 22,49 & 23,28 & 22,88 & 551,5 & 446,1 & 498,8 & 21,50 & 21,20 & 21,35 \\
\hline A. Acres & 571,3 & 491,5 & 531,4 & 22,89 & 22,60 & 22,74 & 547,1 & 463,3 & 505,2 & 21,97 & 21,31 & 21,63 \\
\hline Média (Mean) & 539,5 & 496,2 & & 22,69 & 23,13 & & $558,6 \mathrm{a}$ & $449,5 b$ & & $22,23 a$ & $21,23 b$ & \\
\hline \multirow[t]{3}{*}{$\mathrm{CV} \%$} & & 17,97 & & & 4,32 & & & 8,27 & & & 5,13 & \\
\hline & \multicolumn{3}{|c|}{$\begin{array}{l}\text { Asas } \\
\text { Wings }\end{array}$} & \multicolumn{3}{|c|}{$\begin{array}{l}\text { Asa/peso vivo } \\
\text { Wings/body weight }\end{array}$} & \multicolumn{3}{|c|}{$\begin{array}{l}\text { Dorso } \\
\text { Back }\end{array}$} & \multicolumn{3}{|c|}{$\begin{array}{l}\text { Dorso/peso vivo } \\
\text { Back/body weight }\end{array}$} \\
\hline & $\begin{array}{c}\text { Macho } \\
\text { Male }\end{array}$ & $\begin{array}{l}\text { Fêmea } \\
\text { Female }\end{array}$ & $\begin{array}{c}\text { Média } \\
\text { Mean }\end{array}$ & $\begin{array}{c}\text { Macho } \\
\text { Male }\end{array}$ & $\begin{array}{l}\text { Fêmea } \\
\text { Female } \\
\end{array}$ & $\begin{array}{c}\text { Média } \\
\text { Mean }\end{array}$ & $\begin{array}{c}\text { Macho } \\
\text { Male }\end{array}$ & $\begin{array}{l}\text { Fêmea } \\
\text { Female }\end{array}$ & $\begin{array}{c}\text { Média } \\
\text { Mean }\end{array}$ & $\begin{array}{c}\text { Macho } \\
\text { Male }\end{array}$ & $\begin{array}{l}\text { Fêmea } \\
\text { Female }\end{array}$ & $\begin{array}{c}\text { Média } \\
\text { Mean } \\
\end{array}$ \\
\hline Ross & 195,9 & 187,5 & 191,7 & 7,78 & 8,60 & 8,19 & 367,4 & 321,8 & 344,6 & 14,59 & 14,66 & 14,63 \\
\hline Cobb & 188,7 & 163,3 & 176,0 & 7,59 & 7,73 & 7,66 & 365,6 & 296,0 & 330,8 & 14,71 & 14,00 & 14,35 \\
\hline A. Farms & 188,1 & 160,9 & 174,5 & 7,30 & 7,65 & 7,48 & 357,2 & 315,6 & 336,4 & 13,90 & 15,01 & 14,45 \\
\hline A. Acres & 188,5 & 162,8 & 175,6 & 7,57 & 7,49 & 7,53 & 368,7 & 320,0 & 344,3 & 14,79 & 14,73 & 14,76 \\
\hline Média (Mean) & $190,2 a$ & $168,6 b$ & & 7,56 & 7,87 & & $364,7 \mathrm{a}$ & $313,4 b$ & & 14,60 & 14,50 & \\
\hline CV\% & & 7,11 & & & 8,02 & & & 6,24 & & & 5,51 & \\
\hline
\end{tabular}

Letras diferentes nas linhas indicam diferença estatística significativa.

Minor letters in the rows indicates statistical difference.

$\mathrm{CV}=$ coeficiente de variação.

$C V=$ coefficient of variation.

Tabela 7 - Interação estatística entre o peso dos cortes e suas relações com o peso vivo (PV) aos 44 dias de idade Table 7 - Cuts weight (grams) and relation between cuts weight and live weight (\%) at 44 days of age

\begin{tabular}{|c|c|c|c|c|c|c|}
\hline & \multicolumn{3}{|c|}{$\begin{array}{c}\text { Cabeça+pescoço+pés }(\mathrm{g}) \\
\text { Head }+ \text { neck }+ \text { feet }\end{array}$} & \multicolumn{3}{|c|}{$\begin{array}{c}\text { Cabeça }+ \text { pescoço }+ \text { pés/PV }(\%) \\
\text { Head }+ \text { neck }+ \text { feet/bodyweight }\end{array}$} \\
\hline & $\begin{array}{l}\text { Macho } \\
\text { Male }\end{array}$ & $\begin{array}{l}\text { Fêmea } \\
\text { Female }\end{array}$ & $\begin{array}{l}\text { Média } \\
\text { Mean }\end{array}$ & $\begin{array}{l}\text { Macho } \\
\text { Male }\end{array}$ & $\begin{array}{l}\text { Fêmea } \\
\text { Female }\end{array}$ & $\begin{array}{l}\text { Média } \\
\text { Mean }\end{array}$ \\
\hline Ross & 256,7 & 202,3 & 229,5 & 10,20 & 9,23 & 9,71 \\
\hline Cobb & 201,3 & 194,2 & 197,7 & 10,37 & 9,19 & 9,78 \\
\hline A. Farms & 255,3 & 185,2 & 220,2 & 9,94 & 8,81 & 9,37 \\
\hline A Acres & 261,3 & 204,4 & 232,8 & 10,49 & 9,39 & 9,94 \\
\hline Média & $243,6 b$ & $196,5 \mathrm{a}$ & - & $10,25 \mathrm{a}$ & $9,15 \mathrm{~b}$ & - \\
\hline \multicolumn{7}{|l|}{ Mean } \\
\hline CV\% & & 19,77 & & & 5,37 & \\
\hline
\end{tabular}

Letras diferentes nas linhas indicam diferença estatística significativa.

Minor letters in the rows indicates statistical difference.

$\mathrm{CV}=$ coeficiente de variação.

$C V=$ coefficient of variation. 


\section{Conclusões}

Nas condições do presente estudo, os machos tiveram desempenho e peso de carcaça superiores às fêmeas, contudo nas características de rendimento de carcaça mostraram-se semelhantes.

A linhagem Ross apresentou melhor conversão alimentar em relação às demais linhagens, aos 44 dias de idade, e a linhagem Cobb, menor consumo de ração até os 48 dias de idade.

Não houve diferenças entre as linhagens no rendimento de carcaça ou de cortes.

Assim, todas as linhagens estudadas apresentam um rendimento zootécnico satisfatório, devendo a escolha da empresa por uma ou outra linhagem ser baseada em critérios de mercado.

\section{Agradecimento}

\section{Ao ABATEDOURO SÃO SALVADOR} (Itaberaí, GO), pelo fornecimento dos materiais necessários à pesquisa (ração, instalações); à ASA ALIMENTOS (Brasília, DF), pelo fornecimento das aves; e ao CNPq.

\section{Literatura Citada}

BIHAN-DUVAL, E.L.; MIGNON-GRASTEAU, S.; MILLET, $\mathrm{N}$. et al. Genetic analysis of a selection experiment on increased body weight and breast muscle weight as well as on limited abdominal fat weight. British Journal of Nutrition, v.39, n.3, p.346-353, 1998 .

FARRAN, M.T.; KHALIL, R.F.; UWAYJAN, M.G. et al. Performance and carcass quality of commercial broiler strains. Journal of Applied Poultry Research, v.9, n.3, p.252-257, 2000.

HOLSHEIMER, J.P.; VEERKAMP, C.M. Effect of dietary energy, protein level and lysine content of on performance and yield of two strains of male broiler chicks. Poultry Science, v.66, n.5, p.872-879, 1992.

MENDES, A.A. Efeito de fatores genéticos, nutricionais e de ambiente sobre o rendimento de carcaças de frangos de corte. Botucatu: Universidade Estadual Paulista, 1990. 103p. Tese (Livre Docência) - Universidade Estadual Paulista, 1990.
MENDES, A.A.; GARCIA, E.A.; GONZALEZ, E. et al. Efeito de linhagem e idade de abate sobre o rendimento de carcaça de frangos de corte. Revista da Sociedade Brasileira de Zootecnia, v.22, n.3, p.466-472, 1993.

MOGYCA, N.S., CAFÉ, M.B., SCHAITL, M. et al. Desempenho e rendimento de carcaça e cortes de duas linhagens de frangos de corte. In: CONFERÊNCIA APINCO DE CIÊNCIA E TECNOLOGIAS AVÍCOLAS, 1996, Curitiba. Trabalhos de pesquisa... Campinas: Fundação Apinco de Ciência e Tecnologia Avícolas, 1996. p.72.

MURAKAMI, A.E.; NERILO, N.; FURLAN, A.C. et al. Desempenho, rendimento de carcaça, cortes e desossa de três linhagens comerciais de frangos de corte. In: CONFERÊNCIA APINCO DE CIÊNCIA E TECNOLOGIA AVÍCOLAS, 1995, Curitiba. Trabalhos de pesquisa... Campinas: Fundação Apinco de Ciência e Tecnologia Avícolas, 1995. p.279-280.

RABELLO, C.B.V.; COTTA, J.T.B.; TEIXEIRA, A.S. et al. Avaliação do rendimento de carcaça de três linhagens de frangos de corte. In: CONFERÊNCIA APINCO DE CIÊNCIA E TECNOLOGIAS AVÍCOLAS, 1996, Curitiba. Trabalhos de pesquisa... Campinas: Fundação Apinco de Ciência e Tecnologia Avícolas, 1996a. p.78.

RABELLO, C.B.V.; COTTA, J.T.B.; TEIXEIRA, A.S. et al. Avaliação do desempenho zootécnico de três linhagens de frangos de corte. In: CONFERÊNCIA APINCO DE CIÊNCIA E TECNOLOGIAS AVÍCOLAS, 1996, Curitiba. Trabalhos de pesquisa... Campinas: Fundação Apinco de Ciência e Tecnologia Avícolas, 1996b. p.79.

RABELLO, C.B.V.; COTTA, J.T.B. Rendimento em partes em relação à carcaça pronta para assar de diferentes linhagens de frangos de corte. In: CONFERÊNCIA APINCO DE CIÊNCIA E TECNOLOGIAS AVÍCOLAS, 1997, Campinas. Trabalhos de pesquisa... Campinas: Fundação Apinco de Ciência e Tecnologia Avícolas, 1997. p.43.

SILVA, M.A. Desempenho produtivo de linhagens de corte e poedeiras em desenvolvimento na Universidade Federal de Viçosa. In: CONGRESSO BRASILEIRO DE REPRODUÇÃO, 8., 1989, Belo Horizonte. Anais... Belo Horizonte: Colégio Brasileiro de Reprodução Animal, 1989. p.305-312.

SOUZA, P.A.; SOUZA, H.B.A.; CAMPOS, F.P. et al. Desempenho e características de carcaça de diferentes linhagens comerciais de frango de corte. Revista da Sociedade Brasileira de Zootecnia, v.23, n.5, p.782-791, 1994. 